\title{
Education As a Tool of Change among Gujjars :A Case Study of District Pulwama
}

\author{
Dr Syed Damsaz Ali Andrabi (Corresponding author) \\ Higher Education Department Jammu and Kashmir \\ India
}

Tel: 91-96-2264-0951Ｅ-mail: damsaz.andrabi@gmail.com

Received: October 22, 2016 Accepted: November 15, 2016 Published: December 15, 2016

doi:10.5296/ijch.v3i2.10458 URL: http://dx.doi.org/10.5296/ijch.v3i2.10458

\begin{abstract}
Illiteracy is the social evil and can be removed through the appropriate system of education. Gujjars of district Pulwama are in social delima because they are lagging behind in the field of peace and prosperity. Their orthodoxy is the main hurdle in the way of progress. The community is lacking the trained working force. In the district they are among the backwards and same can be realized and marked because of their poor performance in the field of education. Because of lack advancements, their health conditions are very poor in comparison to national level. The standard rate of literary is below the normal level in both the sexes. The condition of women is very miserable. Proper change among them can be brought through proper intervention and mediation of religious preachers.
\end{abstract}

Keywords: Education, Technology, Schools, Orthodoxy, Communication, Poverty

\section{Introduction}

Education is the main instrument on which the superstructure of a country rests. Education is considered as a tool of change like connectivity and peace. Because of lack of modern education the position of Gujjars is very miserable. The various social groups and classes living on margins are always involved in conflict with each other. Their moral fabric is in tatters. Only education can bring necessary changes in their day today life. The same can be used as an important module of progress and their active participation in the field of education. Religious preachers can also play an important role in motivating them towards the new tool besides the religious education. Because religious preachers have too much of dominance over the Gujjar tribes. In real sense they act as advisors and their mediation can boost the socio-economic setup of Gujjar community in district Pulwama. 
The Gujjars migrated to Kashmir in different ways and got settled at different parts of the valley including district Pulwama. They have adopted uniquely to the mountainous environment. Generally as the routine they like to perform pastoralism. Gujjars rear cattle and buffaloes, whereas Bakerwals rear sheep, goats and horses. Livestock is reared by them to fulfill their day today needs. Even the same is used for commercial purposes. Although their main occupation is herding but they undertake cultivation also. Especially the maize emerged as the main crop. The same serves as food as well as fodder for the animals. Most of these were primitive pastoralists but later they also took to agriculture. Agricultural activities have also assumed prominence among the Gujjar communities. However, some of the communities maintained their tradition and are still practising the migratory livestock rearing. From the occupation point of view they can be categorized in three groups

1) Dodhi (Milk producing and trading)

2) Zamindar ( livestock rearing and agriculture)

3) Others (Nomadic professionals)

Jammu and Kashmir state, a border state of India is inhabited by a number of tribal communities who have settled down in all parts of Himalayan range of the state. Initially Jammu and Kashmir had no scheduled tribe recognition as a separate community. It was only in, 1989 that eight communities vide the constitution of Jammu and Kashmir state namely, Balti, Beda, Bot, Brokpa, Changpa, Garra, Mon, Purigpa and later on in the year, 1991,other four communities, Gujjar, Bakerwal, Gaddi and Sippis were also identified as scheduled tribes. Thus raised the total number to twelve. All these tribes were enumerated officially for the first time during the 2001 census. According to census 2001, Gujjar tribe is the most populous having a population of nearly, 763806, thus forming, 69.1 percent of the total scheduled tribe population. The census 2011 shows the entire scheduled tribe (ST) population of the state is, 14,93299 in comparison to, 11,05979 of census 2001. The census scale shows increase in their population. At present the population of Gujjars in Pulwama district is, 22607,only. Almost,98.7 per cent comprised of rural population and only, 1.3 percent is settled in urban areas. 


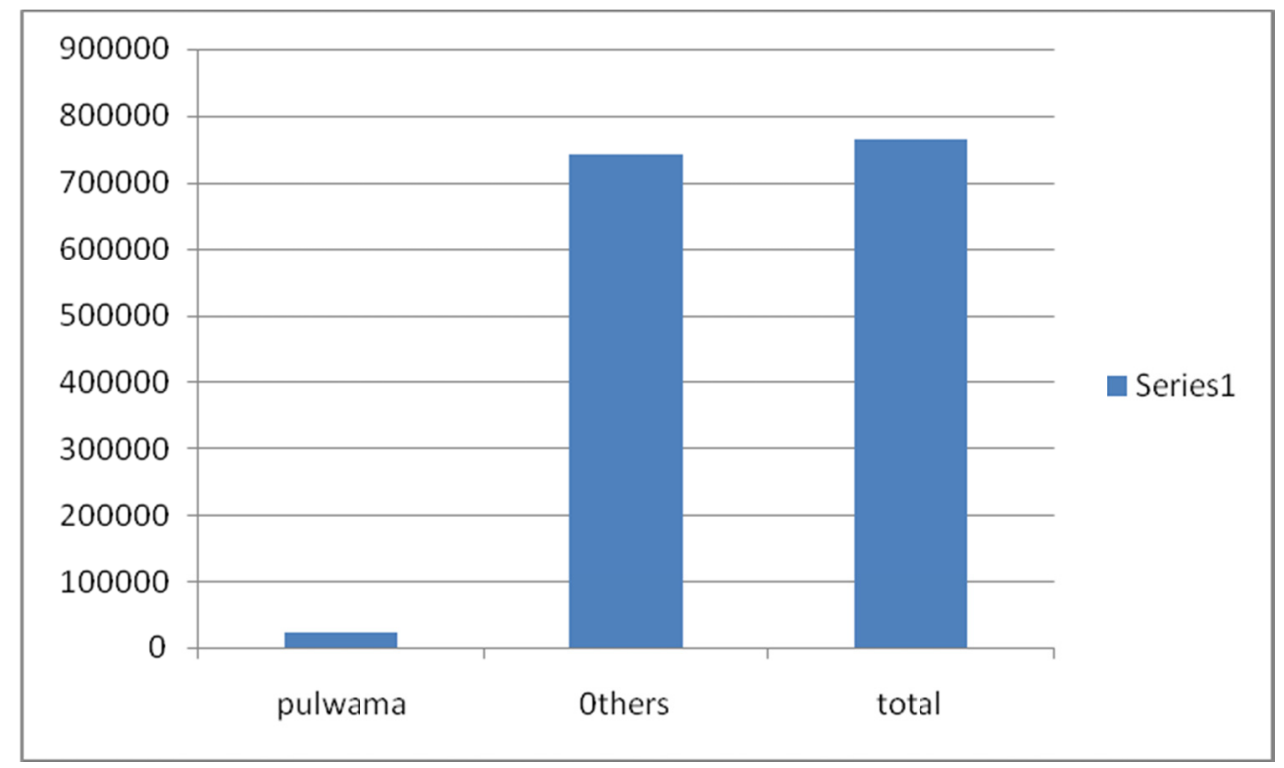

Figure 1. Graphical Display of Gujjar Population

Gujjars in the valley of Kashmir are the third largest ethnic group after Kashmiri speaking Muslims and Hindus. Gujjars are a unique tribe with their own cultural and linguistic identities. Pir Panchal region is considered the home of the Gujjar tribe in Jammu and Kashmir state where we find their main concentration on the slopes and foot hills. The natural atmosphere, location disadvantages and aloofness from the modern life although made this very particular community economically and educationally backward, but their unique tribal culture and distinct heritage remain preserved which is rarely available elsewhere in the world. However there is one important area which can change their life i.e. modern educational system which has great potential in improving the quality of life without disturbing their cultural values .

The Gujjars of whole valley including the Gujjars of Pulwama district were originally Hindus. But during the rule of Mughal king Aurangazeb, 1658-1707.A.D,most of them were converted to Islam but retained their Hindu Gotras. The common Gotras are: Bhati, Chandel, Chauhan, Baniya, Lodha, Bhensi, Chopra, Chechi, and Khatana. Even today some Gotras are found in the areas of Pulwama district. They speak a dialect called as "Gojri" which is different from Dogri and Kashmiri, the major languages of the state. Gujjars have their Khothas or Dhokas called "Deras" in the various areas of Pulwama district.The highly populated areas of Gujjars in Pulwama district are, Tral, Lam, Satoora, Nagbal, Gulshanpora, Machum, Yashgoza, Abhama, and Shadimarg. They are still engaged in their traditional occupation of rearing buffaloes and the sale of milk and other products made of milk like ghee and butter. Their living standard in spite of strong efforts on the whole has remained very miserable and deplorable.

The Gujjars of Pulwama live in Khothas. These are made up of mud and wood who have only one room for the whole family. The Kotha comprised of roughly $30 \times 10$ feet. They are without ventilation and windows. Accustomed of living in such huts with close company of their cattle in the same dwelling. Besides they also cook food in the same: room which keeps them always smoky and unhygienic for humans. Their health condition and residential places 
are abodes of misery. Their children do not have conducive educational environment at home. Most of the Gujjar parents express doubts about the utility of modern education and gave very little value and scope to schooling. The Gujjar children are devoid of proper family care and affection. They suffer from groomy atmosphere around and absence of guidance. They have not yet realised the importance of education as they are primitive and orthodox. Pastoral life has totally separated them from the rest of society. The non availability of Gujjar teachers is the another problem in the way of development. Because of the language problem it becomes dead impossible for the learners of community to understand the basic ideas. So the language of community should be given proper place in school curriculum of state. Introduction of their language in the school curriculum will act as principle factor for the development of education. Popularization of their language can incline them towards the new design, if the authorities are really interested to change their socio-economic set up. The Gujjars of Pulwama district have always received a step-motherly treatment from the authorities from time and again. To involve them in the activities of latest trends there is a need of strong efforts for the betterment of living standard.The Gujjars are one of the most backward communities of the district. The backwardness is all-around and particularly marked in scantly educational advancement \& unhealthy living conditions. The standard of literacy among them is very low.

The overall literacy rate of the scheduled tribes (STs) is, 37.5 percent in 2001 census. This is much lower than the national average of, 47.1 percent aggregated for all scheduled tribes . Male and female literacy rates, 48.2 and, 25.5 percent are much below if compared to those recorded by all scheduled tribes at the national level, $59.2 \& 34.8$ percent. The rate of literacy among Gujjars of valley was, 31.7 percent in 2001, while as among the females of community it was only, 20.4 percent . Both the levels of literacy are beyond the level of change. Under such circumstances there is no chance of improvement. Among the larger tribes, Balti, Bot, Purigpa and Brokpa have registered higher literacy rate whereas Gujjar, Gaddi and Bakarwals have a lower literacy rate than that of national average.The literacy rate among the Gujjars of Pulwama at present is, 17.4 percent while as among others it is, 66.21 percent .

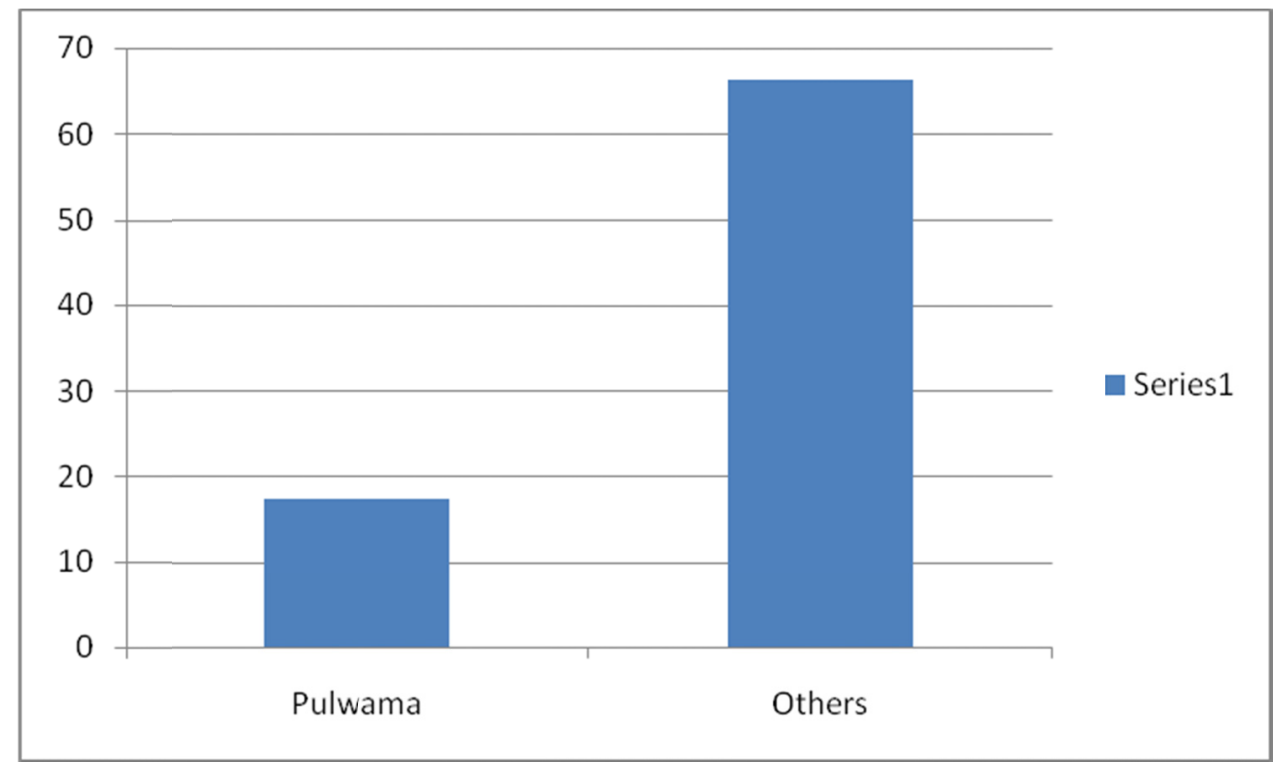

Figure 2. Literacy Rate of Gujjars and others in District Pulwama 
The need of the hour is to change their position through the mediation of religious preachers called by them as Pirs, because the Gujjars are too superstitious due to illiteracy and backwardness which had made them narrow minded. Their belief in Pirs is unparalleled . Taweez (amulets) for them and castles is a panacea. However the same had contributed a lot towards the present. Chances of positive change will occur with the real involment of religious preachers in the said field. The religious advisors too should be trained with the latest trends in the field of modern education. Education is itself a guarantee of peace and progress. Measures should be undertaken by involving and using the latest techniques of modern educational system focusing for removing social evils and enlightening them with new ideas breaking down all the traditional system which has entrapped them in the system of ignorance. A self concept can be developed through the appropriate system of education. This can help in improving the knowledge among them about the changing trends. Gujjars differ in the opinions, in concepts and various other things with the rest of society. To uplift them, the authorities have to prioritize the education for them at the gross root level so to arm and equip their children with educational knowledge and to enable them to compete with rest of population.

Although schooling facility is available for all migratory populations during winter in the form of stationary and permanent government schools at different places all over the state. But at the summer locations where the good numbers of nomadic children are available who move there with parents, the educational facilities are less. Financial problems are a big obstacle in the way of development among the Gujjars. Parents need the help of their children in farming and in tending the cattle. Because of the miserable condition they are not in a position to provide the nominal school fee to their children. Such is the lack of awareness even some Gujjars do not know what the schools are meant for. Authorities have not made any such positive effort to make them aware about the benefits of education. Almost, 83 percent Gujjar children in Pulwama district are being deprived of schooling because their families move to pastures in summer. The long distance from home to school is among the measure causes of backwardness among the socially deprived people identified as Gujjars.

Gujjars of Pulwama have difference in terms of their socio-economic and cultural advancements. Some of them used to live in forests and on hill tops, whereas others have settled at the plains. Some have opted agriculture and others remained completely dependent on forest produce. However in general as per the constitution of country all the scheduled tribes have been declared as the weaker sections of the society. Efforts and provisions have been made to bring about socio- economic change among them. With the support of administration Gujjars have started a number of social movements to change the narrow mindedness within the groups and families. Tribal cultures have been revived to preserve the taditions of Gujjar community. These movements resulted certainly in an increased cultural and social consciousness among the tribes in various local areas of Pulwama. In order to make the groups more effective, it is very necessary to reduce the tribal economic distinctions.

Gujjars generally socialize within their own fold and not with the other people of peripheral areas. Right from the beginning they possess the cunning nature and in all parts of valley are considered as criminals. They have nothing in common with other Muslims in customs, manners, dress, habits and food. Marriages outside their own tribe are not preferred. Gujjars 
used to initiate and forward marriage proposals through a person know as Gujjar Barber (Nai). But with changing trends the old customs has got changed and now mostly friends and relatives perform this particular practice. Mostly selection is made by the parents, especially by females not by the younger ones themselves. The rate of divorce in Gujjar community is very low. The dowry system is low and simple. The dowry items consists of buffalo, cow, goat, sheep, spinning wheel and other domestic articles. Marriage bonds are maintained and performed in according to prescribed religious laws and social sanctions. During marriage ceremonies a distinguishing feature and practice of wrestling is performed by them to entertain the guests. Gujjars of Pulwama are well organized into Kabeels (Clans). Each Clan has its own leader called as Gujjar Mukhdam and has a unique system of Gujjar councils called as Jirga.They are normally run by the elder male of clan.Matters of disputes may be civil ,criminal or religious are decided by them. Lot of influence is exercised by them over the tribes.Nowadays local Panchayat heads also play a role in their socio-economic life, but not as much as their own councils. This shows the close connectivity of past cultures among the different groups of people.The overall position of women in ancient and medieval Kashmir was very healthy as compared to the present position of women among the Gujjars. Their very position in Pulwama district is very miserable and painful. Females are begging from door to door for survival.Their position is beyond the levels of human expectations and education for them is the distant dream. The biggest obstacle in the way of education is the early marriage of both sexes . Normally, 82 percent Gujjars parents prefer early marriage of their sons and daughters. The marriagable age of males is between the age group of, 15 to 18 years and among females is between, 12 to 15 years only while as among others it is between, 30 to 35 years of age. Another major cause of educational backwardness is the joint family system prevalent within the tribes. Almost 78 percent live in joint family and only 22 percent in nuclear family system. In such circumstances it not possible for them to receive the education and they are being deprived of the fundamental right of "right to education". So the ultimate responsibility for moulding their climate of opinion in favour of new innovations lies with the administration as well as educational research cum-extension institutional programmes supervised by experts not by general employees of the state. As a routine all the programmes related to deprived communities are being supervised by the district heads who do not have any specialization in the relevant field. The need of the hour is the complete overhauling of the system.

To socialize the Gujjars community of Pulwama requires constructive standards of literary, radical changes in teaching methods and growth of educational facilities can bring changes in the social structure of Gujjars. Without proper educational development it will be wellneigh impossible to solve the looming problems of Gujjars. Trained workers and developing cardes of modern science and technology can help to bring necessary changes in their day today life. Despite of the fact that huge amounts are being spent through a variety of new developmental schemes which benefits only marginal and small groups among the Gujjars. But unfortunately the evaluation results of these measures are not satisfactory but far behind the expected norms. The real and basic reason for such unhealthy trend is due to the ill conceived programmes, non seriousness of implementing agencies and absence of accountability. In order to have proper investment all developmental initiatives related to Gujjars of Pulwama district should be re-examined and re-assessed afresh. 


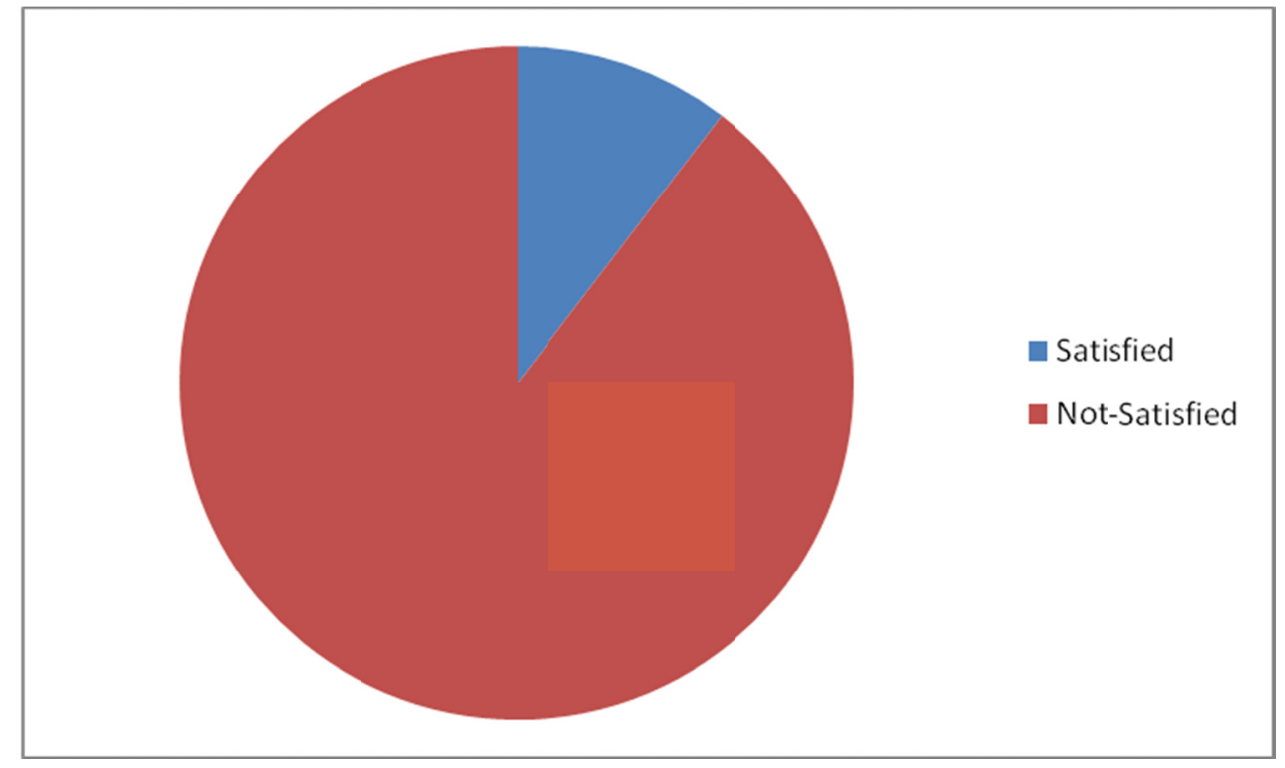

Figure 3. Response of Gujjars in District Pulwama towards Govt. Polices

This is the real time when we all should realize the importance of problem and the causes of educational backwardness among the Gujjars, needs to be identified in order to find out the solution of serious problem. This can be achieved only through a purposeful research in the field of education. Education has a great role to play in the upliftment and in bringing them in line with the rest of population. Education only can make people to think in terms of oneness without undivided locality of the motherland.

\section{Conclusion}

The position of Gujjars in the areas of district Pulwama is below the poverty line. Inspite of constant pursuance, their position remains unchanged. Although they are having the rich cattle wealth, but they are not in a position to utilize the wealth properly. Their position can be changed only with the positive support of trained religious preachers because they exercised too much of influence over them.Really their lifestyle is horrible, miserable, touching and beyond one's imagination.

\section{References}

Ali, C. R. (2001). A Short History of the Gujjars, Begum AkhbarJahan foundation, Jammu.

Ali, M. (1997). Geography of Jammu; A Regional Analysis, Delhi.

Anita, S. (2009). The Bakarwals of Jammu and Kashmir, Navigating Through Nomadism, New Delhi.

Bhardwaj. (1994). History and Culture of Himalayan Gujjars. Jay Kay publishers.

Henny, S. (1998). The Kashmiri Gujjar, A study of Cultural Choice in North India, Delhi.

Kapur, M. L. (1999). History of Jammu and Kashmir State. New Delhi.

Karl, K. (1958). Pahari Miniature Painting. New Delhi.

Kaul, P. N. (1962). A History of Kashmir, Political, Social, Cultural, Delhi. 


\section{Macrothink}

Rahi, J. (2011). The Gujjar Tribe of Jammu and Kashmir. Srinagar.

Singh, J. (2004). The Economy of Jammu and Kashmir. Delhi.

Singh, N. K. (2000). Islamic Heritage of Kashmir. Srinagar.

Siraj, M. (2003). Towards Peace in Jammu. Kashmir and Ladakh, Delhi.

Vaid, S. P. (2014). Paharies of Jammu and Kashmir. Jammu.

\section{Copyright Disclaimer}

Copyright for this article is retained by the author(s), with first publication rights granted to the journal.

This is an open-access article distributed under the terms and conditions of the Creative Commons Attribution license (http://creativecommons.org/licenses/by/3.0/). 